\title{
Lipid Profile among the Diabetic and Non-Diabetic Obese Patients
}

\author{
Djénèbou Traoré1, Aminata Hamar Traoré1, Djeneba Sylla Sow ${ }^{1}$, Massama Konaté1, \\ Amadou Koné1, Hadiaratou Doumbia N’Diaye1, Modibo Mariko1, Ibrahim Amadou Dembélé2, \\ Moctar Bah', Bah Traoré1, Djibril Sy², Ichaka Menta ${ }^{3}$, Hamidou Oumar Ba ${ }^{3}$, Nongoba Sawadogo4, \\ Abdramane Traoré5, Assa Traoré Sidibé1, Assétou Soukho Kaya², Abdel Kader Traoré2, \\ Mamadou Dembélé2, Hamar Alassane Traoré2
}

\footnotetext{
${ }^{1}$ Service of Internal Medicine and Endocrinology of Hospital of Mali, Bamako, Mali

${ }^{2}$ Service of Internal Medicine of Point G University Hospital Center, Bamako, Mali

${ }^{3}$ Service of Cardiology of Gabriel Touré University Hospital Center, Bamako, Mali

${ }^{4}$ Service of Internal Medicine of $C H R$ de Kaya, Kaya, Burkina Fasso

${ }^{5}$ Service of Internal Medicine of Kati University Hospital Center, Bamako, Mali

Email:monopolytra@yahoo.fr
}

How to cite this paper: Traoré, D., Traoré, A.H., Sow, D.S., Konaté, M., Koné, A., N’Diaye, H.D., Mariko, M., Dembélé, I.A., Bah, M., Traoré, B., Sy, D., Menta, I., Ba, H.O., Sawadogo, N., Traoré, A., Sidibé, A.T., Kaya, A.S., Traoré, A.K., Dembélé, M. and Traoré, H.A. (2018) Lipid Profile among the Diabetic and Non-Diabetic Obese Patients. Open Journal of Internal Medicine, 8, 89-97.

https://doi.org/10.4236/ojim.2018.81010

Received: February 5, 2018

Accepted: March 23, 2018

Published: March 26, 2018

Copyright $\odot 2018$ by authors and Scientific Research Publishing Inc. This work is licensed under the Creative Commons Attribution International License (CC BY 4.0). http://creativecommons.org/licenses/by/4.0/

\section{Open Access}

\begin{abstract}
Objective: To study the lipid profile among the diabetic and non-diabetic obese patients. Methods: It was a descriptive and prospective study carried out over a period of 9 months from March to December 2010. It concerned all the patients who came for consultation in endocrinology at the internal medicine of Point G University Hospital Center and at the National Center for Diabetes Research. All the patients were included without any gender or age difference, voluntary and with a BMI $\geq 30 \mathrm{~kg} / \mathrm{m}^{2}$. Results: Out of the 1543 patients received in consultation, we had identified 178 obese people that is to say 11, $53 \%$ of the cases. Among these cases 60 abided by our criteria with 30 diabetic patients and 30 non-diabetic ones. The average age was $45.83 \pm 14.68$ years old; $73.3 \%$ were more than 40 years old. The sex ratio was 0.07 . Two third (66.7\%) of our patients limited their eating diet to the three main meals/day and $61.7 \%$ were sedentary. The notion of family obesity was found in $93.4 \%$ of the cases, of family diabetes in $58.3 \%$ of the cases, of past personal medical history of hypertension in $43.3 \%$ of the cases. It was about an android obesity in $91 \%$ and Gynoid in $9 \%$ of the cases. The BMI was $55 \%$ of the cases comprised between $30-34.9 \mathrm{~kg} / \mathrm{m}^{2}$. The lipid profile noticed was: A hypertriglyceridemia: $33 \%$ of diabetic patients and $10 \%$ of non-diabetic patients, a high LDL cholesterol: $37 \%$ of diabetic patients and $30 \%$ of our diabetic patients, a HDL hypocholesterolemia: $40 \%$ of the diabetic patients and $20 \%$ of the non-diabetic patients, a total hypercholesterolemia: $37 \%$ of the diabetic patients and $23 \%$ of non-diabetic patients. A hyperglycemia was noticed in
\end{abstract}


$13.3 \%$ of non-diabetic patients. Conclusion: The frequency of metabolic troubles were higher in obese diabetic patients compared to non-diabetic obese patients mainly the hypertriglyceridemia.

\section{Keywords}

Diabetes, Obesity, Dyslipidemia

\section{Introduction}

Obesity is a chronic disease which corresponds to an excess of fat having some dangerous consequences on people's health.

The factors causing the development of obesity are multiple and intricate: $\mathrm{Ca}$ loric density of the eating diet, sedentary lifestyle, psychological factors, role of heredity, socio-economic context [1]. Its definition is based on the calculation of the body mass index $\left(\mathrm{BMI}=\right.$ weight $/$ height ${ }^{2}$ : Weight in $\mathrm{kg}$ and height in $\left.\mathrm{m}^{2}\right)$. A BMI $\geq 30 \mathrm{~kg} \backslash \mathrm{m}^{2}$ defines obesity in the cases of both sexes for the adult [2].

Obesity is frequent; it concerns $12.4 \%$ of the adult population in France, that is to say around 6 millions of people; $0.8 \%$ of the population presents a mass obesity (BMI $\left.\geq 40 \mathrm{~kg} \backslash \mathrm{m}^{2}\right)$. In Mali $20.4 \%$ of patients ageing between $18-35$ years are obese in cardiology [3], and $26.7 \%$ of patients ageing between $18-85$ years are obese in the diabetic population [4].

Lipid troubles are very frequent among the diabetic patients of type 2 . The high rate of cholesterol and de triglyceride are known for long time as a high risk factor for cardiovascular diseases [5].

The presence of a dyslipidemia on a diabetic terrain is a factor of supplementary risk [5].

The overall goal was study To study the lipid profile among the diabetic and non-diabetic obese patients.

\section{Methodology}

Area of the study: the study was carried out at the Service of Internal Medicine of University Hospital Center point $G$ and at the National Center for Diabetes Research.

Type and period of the study: It was a transversal and analytical study implemented over a period of 9 months going from March 2010 to December 2010.

Study Population: It was made of the entire number of patients who came for endocrinology consultation at the internal medicine service of University Hospital Center point G, or at the National Center for Diabetes Research. Two groups were targeted: 30 diabetic patients and 30 non-diabetic patients.

Sampling: the sample concerned all the patients consulted during the period of the study.

Inclusion Criteria: Any patient from both sexes, without any age limitation, 
volunteer and having a body mass index (BMI) higher or equal to $30 \mathrm{~kg} / \mathrm{m}^{2}$.

Criteria of Non-inclusion: Patients having a BMI inferior to $30 \mathrm{~kg} / \mathrm{m}^{2}$, those refusing to accept the protocol, those consulted after the period of the study and those having not benefited from complementary examinations.

\section{Studied Variables}

Clinic Variables: The calculation of the BMI in consistence with weight and height following the formula of Quetelet: BMI $=$ Weight $(\mathrm{kg}) /\left(\right.$ Height in $\left.\mathrm{m}^{2}\right)$.

Three types are defined: BMI between 30 and $34.9=$ moderated obesity; BMI between 35 and $39.9=$ severe obesity; BMI $\geq 40=$ morbid obesity.

The measure of the height (TT): we have used the criteria of the International Federation of Diabetes [2], with man: normal if $\leq 94 \mathrm{~cm}$. if $>94 \mathrm{~cm}$, abdominal obesity; with woman: normal if $\leq 80 \mathrm{~cm}$; if $>80 \mathrm{~cm}$, abdominal obesity.

The calculation of the relation of the height/the size of hip:: we have used the criteria of the International Federation of Diabetes. With man: normal Value if the relation of the height/the size of hip $\leq 1$; if $>1$ android obesity. With woman: normal value if the relation of the height/the size of hip $\geq 0.85$ if $<0.85$ gynoid obesity.

Para-clinic Variables: Glycaemia: normal if comprises between $0.79-1.10 \mathrm{~g} / \mathrm{l}$ that is to say $(4.1-6.1 \mathrm{mmol} / \mathrm{l})$.

Uricaemia: normal if comprises between $200-400 \mu \mathrm{mol} / \mathrm{l}$ that is to say (33 $70 \mathrm{mg} / \mathrm{l})$.

HDL cholesterolemia: normal if $>$ at $0.40 \mathrm{~g} / \mathrm{l}$ that is to say $(1.20-1.70$ $\mathrm{mmol} / \mathrm{l})$.

LDL cholesterolemia: normal if $<$ at $1.60 \mathrm{~g} / \mathrm{l}$ that is to say $(<3.50 \mathrm{mmol} / \mathrm{l})$.

Triglyceridemia: normal if comprises between $0.50-1.5 \mathrm{~g} / \mathrm{l}$ that is to say (0.70 - $1.70 \mathrm{mmol} / \mathrm{l})$.

Total Cholesterolemia: normal if comprises between $1.5-2.20 \mathrm{~g} / \mathrm{l}$ that is to say (3.88 - $5.68 \mathrm{mmol} / \mathrm{l})$.

HbAlc: inferior or equal to $7 \%$.

Data Analysis: The processing and analysis of the data were done through the softwares SPSS version 10.0 and Microsoft Word Office 2007. We have retained $\mathrm{p}<0.05$ as the point of signification for statistical tests.

\section{Results}

Out of a total of 1543 patients in consultation during the period of the study, we identified 178 obese patients among whom 60 abided by our criteria of inclusion with 30 diabetic patients and -30 non-diabetic patients. The average age was $45.83 \pm 14.68$ years old, among whom $73.3 \%$ were older than 40 . The sex ratio was 0.07 in each group. The household keepers represented $51.7 \%$ of our series. Sixty six point seven percent $(66.7 \%)$ of our patients were limiting their eating diet to the three main meals/day. Sixty one point seven percent $(61.7 \%)$ of our patients were sedentary. The past family medical history of obesity and diabetes was respectively found in $93.4 \%$ and $58.3 \%$ of the cases. Forty three point three 
percent (43.3\%) of our patients were known hypertensive ones.

Thirty percent (30\%) of our patients have consulted for diabetes and $18.7 \%$ for obesity (as shown in Table 1).

Android obesity was present in $100 \%$ and $91 \%$ among women. Hypertriglyceridemia was present in $33 \%$ of the diabetic patients and $10 \%$ among non-diabetic patients (as shown in Figure 1).

A high LDL cholesterol was present in $37 \%$ of the diabetic patients and $30 \%$ among non-diabetic patients (as shown in Figure 2).

A HDL hypocholesterolemia was found in $40 \%$ of the diabetic patients and $20 \%$ among non-diabetic patients (as shown in Figure 3 ).

Table 1. Distribution of patients by reason of consultation or hospitalization.

\begin{tabular}{ccc}
\hline Reason for consultation & Numbers $(\mathrm{n})$ & Frequency \% \\
\hline Diabetes & 18 & 30 \\
Obesity & 12 & 18.7 \\
Syndrome polyuropolydipsic & 11 & 18.3 \\
hyperthyroidism & 10 & 18 \\
Bilateral gonalgia & 3 & 5 \\
Joint pain & 2 & 3.3 \\
Unexplained effort dyspnoea & 2 & 3.3 \\
Sleep Apnea & 1 & 1.7 \\
HBP & 1 & 1.7 \\
Total & 60 & 100 \\
\hline
\end{tabular}

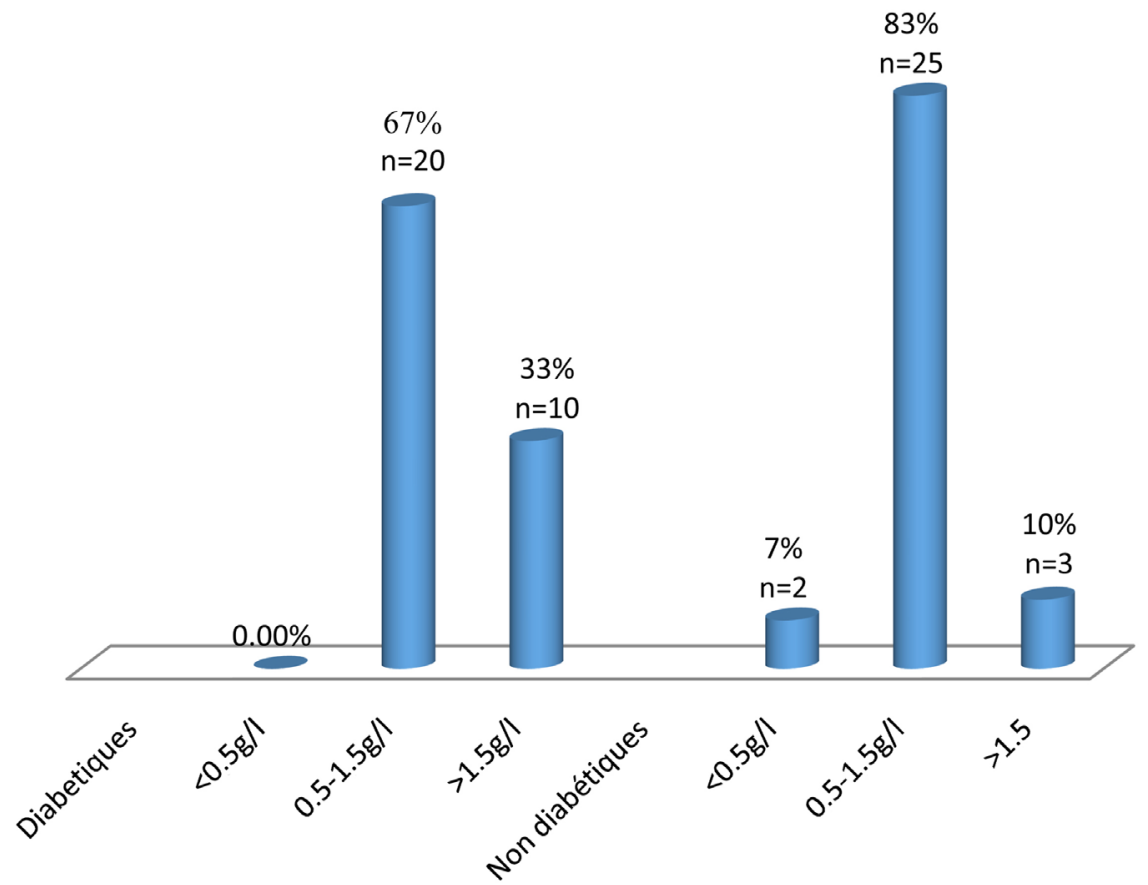

Figure 1. Distribution of patients according to triglyceride levels and the concept of diabetes. 


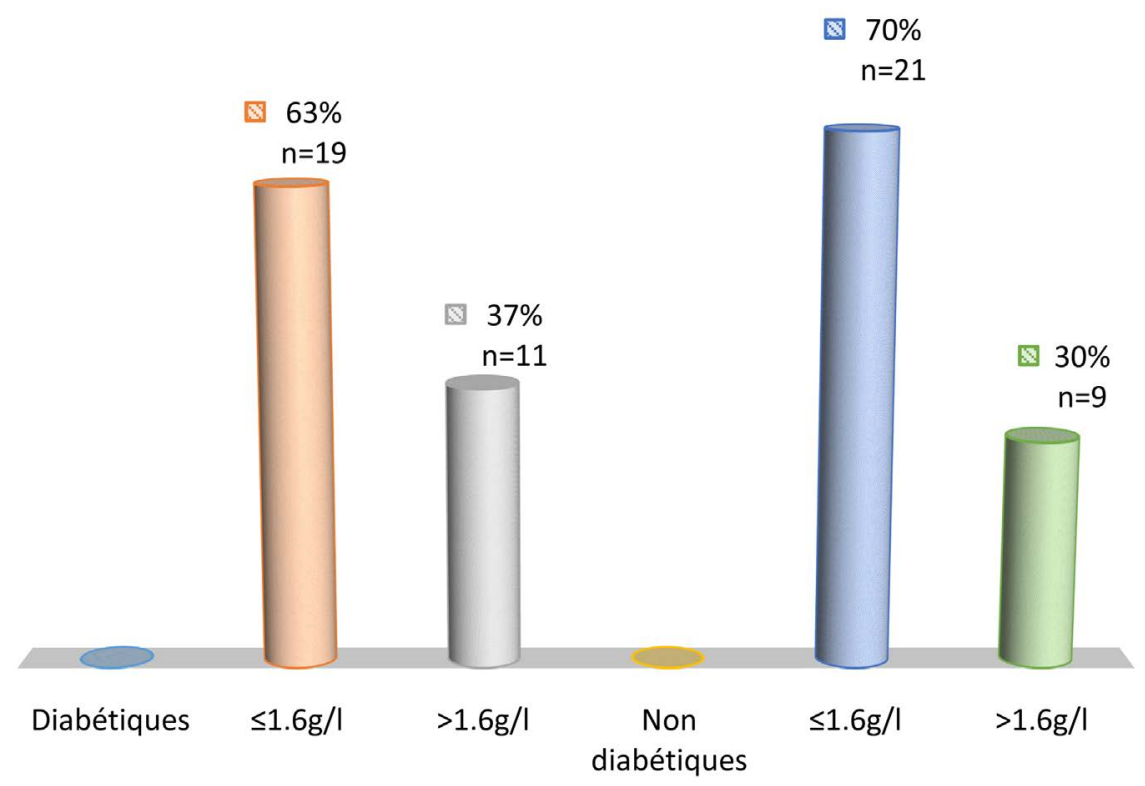

Figure 2. Distribution of patients according to LDL cholesterol and the concept of diabetes.

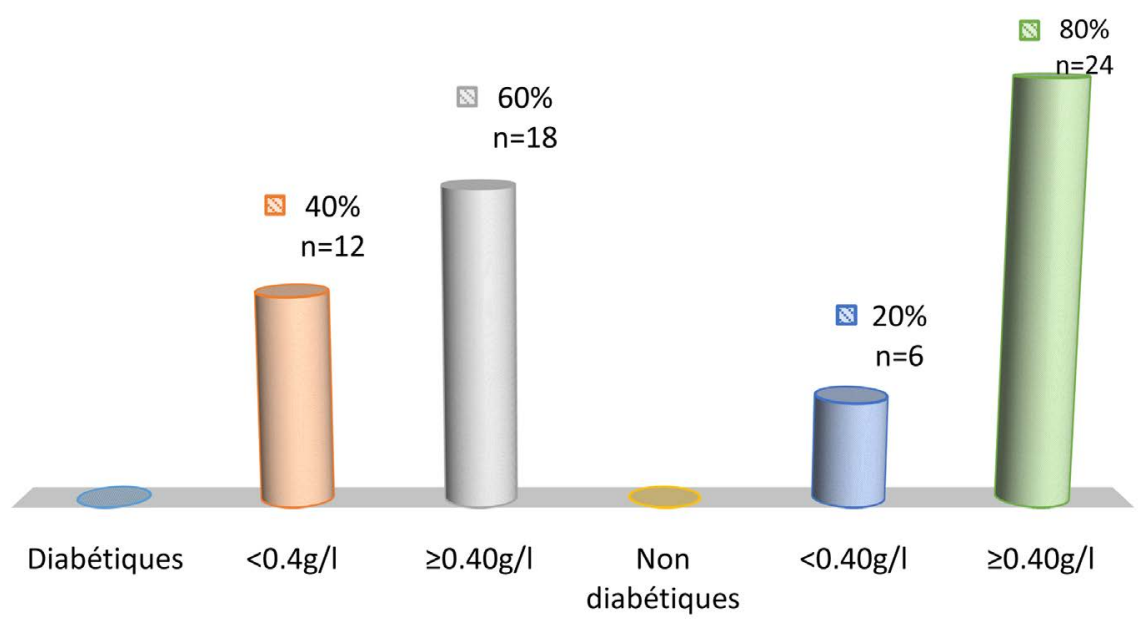

Figure 3. Distribution of patients according to the HDL cholesterol level and the concept of diabetes.

A total hypercholesterolemia was found in $37 \%$ of the diabetic patients and $23 \%$ among non-diabetic patients (as shown in Figure 4).

Hyperuricemia was found in $24 \%$ of the diabetic patients and $10 \%$ among the non-diabetic patients. Eighty seven percent $(87 \%)$ of diabetic patients had a badly balanced diabetes based on glycated haemoglobin $(>7 \%)$. Eighty six point seven $(86.7 \%)$ of our non-diabetic patients had a normal glycaemiaagainst $13.3 \%$ who were in hyperglycemia non-diabetic.

Sixty eight point three $(68.3 \%)$ of our patients were indifferent to obesity (as shown in Table 2).

There was no significant statistical relation between the number of daily meals and the degree of obesity $(\mathrm{p}=0.840)$. We did not notice any significant statistical 


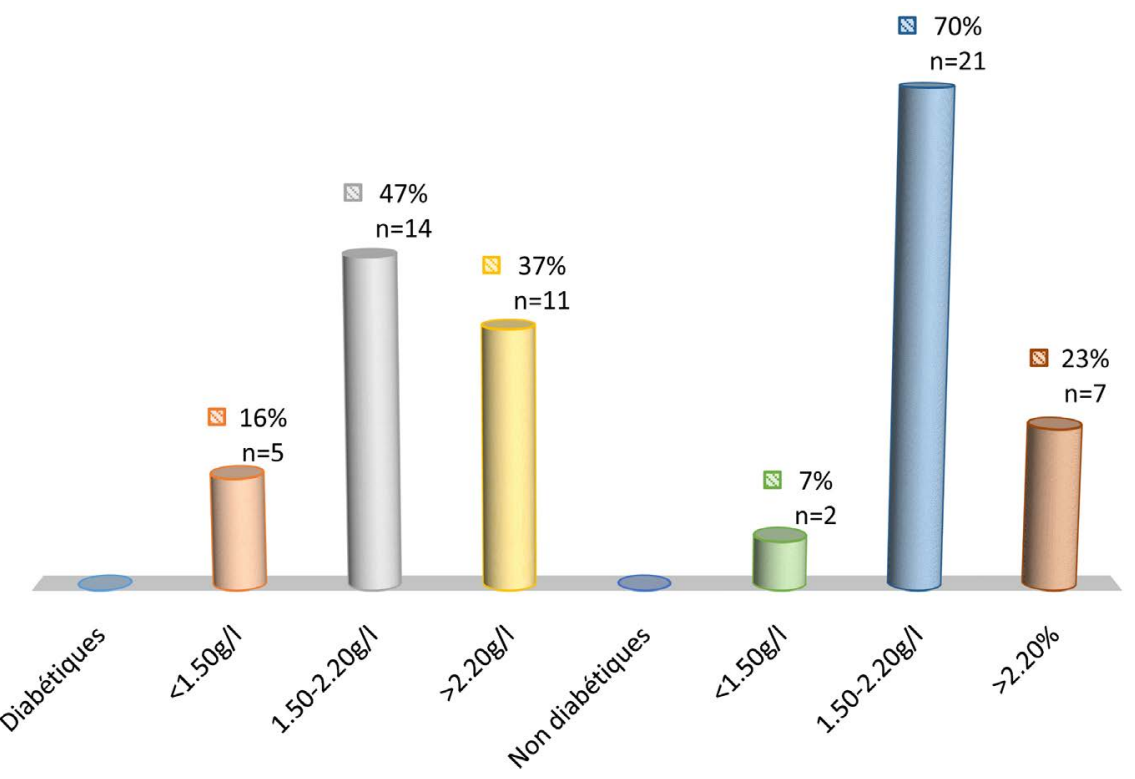

Figure 4. Distribution of patients according to the total cholesterol level and the concept of diabetes.

Table 2. Distribution of patients by reason of consultation or hospitalization.

\begin{tabular}{ccc}
\hline Psychological reaction of patients & Numbers $(\mathbf{n})$ & Fréquency $\%$ \\
\hline Indifference & 41 & 68.3 \\
Worry & 15 & 25 \\
Social pride & 3 & 5 \\
Anger & 1 & 1.7 \\
Total & 60 & $100 \%$ \\
\hline
\end{tabular}

correlation between the degree of obesity and the physical activity $(p=0.861)$.

The degree of obesity was not linked to the rate of triglycerides $(p=0.792)$, to the rate of total cholesterol $(\mathrm{p}=0.894)$ neither to that of LDL cholesterol $(\mathrm{p}=$ 0.617). It existed a significant statistical relation between the degree of obesity and the rate of HDL cholesterol $(\mathrm{p}=0.005)$. The indifference was more frequent among patients having a moderated obesity than the others that is to say $45 \%$ of the cases ( $\mathrm{p}=0.156)$ (as shown in Table 3 ).

It existed a significant statistical relation between the notion of diabetes and the rate of triglycerides $(\mathrm{p}=0.042)$. There was not a significant statistical difference between the rate of LDL cholesterol and the notion of diabetes $(p=0.584)$ (as shown in Table 4).

\section{Commentary and Discussion}

The study was carried out at the service of internal medicine of University Hospital Center point $G$ and at the National Center for Diabetes Research. It had as limitation the reduction of the size of the sample due to the duration of the study. 
Table 3. Relationship between psychological reaction and degree of obesity.

\begin{tabular}{|c|c|c|c|c|c|c|c|c|}
\hline \multirow{3}{*}{$\begin{array}{l}\text { Reactions } \\
\text { psychological } \\
\text { patients }\end{array}$} & \multicolumn{8}{|c|}{ Degree of obesity } \\
\hline & \multicolumn{2}{|c|}{$\begin{array}{l}\text { Obesity } \\
\text { Moderate }\end{array}$} & \multicolumn{2}{|c|}{$\begin{array}{c}\text { Obesity } \\
\text { Severe }\end{array}$} & \multicolumn{2}{|c|}{$\begin{array}{l}\text { Obesity } \\
\text { morbid }\end{array}$} & \multicolumn{2}{|c|}{ Total } \\
\hline & $\mathrm{n}$ & $\%$ & $\mathbf{n}$ & $\%$ & $\mathbf{n}$ & $\%$ & $\mathbf{n}$ & $\%$ \\
\hline Indifference & 27 & 45 & 11 & 18.3 & 3 & 5 & 41 & 68.3 \\
\hline Worry & 4 & 6.7 & 8 & 13.3 & 3 & 5 & 15 & 20 \\
\hline Anger & 0 & 0 & 1 & 6.7 & 0 & 0 & 1 & 6.7 \\
\hline Social pride & 2 & 3.3 & 1 & 6.7 & 0 & 0 & 3 & 5 \\
\hline Total & 33 & 55 & 21 & 35 & 6 & 10 & 60 & 100 \\
\hline
\end{tabular}

$\mathrm{p}=0.156$

Table 4. Relationship between the concept of diabetes and LDL cholesterol.

\begin{tabular}{cccccccc}
\hline & \multicolumn{9}{c}{ Diabetes } \\
\cline { 2 - 8 } LDL cholesterol & \multicolumn{3}{c}{ Oui } & \multicolumn{3}{c}{ Non } & \multicolumn{2}{c}{ Total } \\
\cline { 2 - 8 } & $\mathrm{n}$ & $\%$ & $\mathrm{n}$ & $\%$ & $\mathbf{n}$ & $\%$ \\
\hline$\leq 1.6 \mathrm{~g} / 1$ & 19 & 31.7 & 21 & 35 & 40 & 66.7 \\
$>1.6 \mathrm{~g} / 1$ & 11 & 18.3 & 9 & 15 & 20 & 33.3 \\
Total & 30 & 50 & 30 & 50 & 60 & 100 \\
\hline
\end{tabular}

$\mathrm{p}=0.584$.

During the implementation of this study, we have found out that $73.3 \%$ of the patients were older than 40 years, with an average age of $45.83 \pm 14.6$ years old. This could be explained by the predominance of obesity which classically touches the adult after 40 years old [2].

The female sex represented $93.3 \%$ with a sex ratio of 0.07 in the two groups.

Charfi [6] finds a female predominance in $80.4 \%$ of the cases in a diabetic population in Tunisia. That could be due to cosmopolitan factors such as menopause, sedentary lifestyle, multi-parity but also the quest for conformity with a referential esthetic model, in developing countries overweight is part of the canons of beauty among the average population.

Household keepers represented $51.7 \%$ of the patients, in accordance with the sedentary character of this professional category it becomes the center of obesity.

In the study $66.7 \%$ of our patients were limiting their eating diet to the three main daily meals. This result is similar to that of $\mathrm{Ba}$ [7] who got similar figures, contrary to the received ideas: obese $=$ overeating.

We found in $93.4 \%$ of our patients a past family medical history of obesity and in $58.3 \%$ a past family medical history of diabetes. This result is closer to that of Traoré [8] who reported that $93.3 \%$ and $80 \%$ of his patients had these past family diseases affiliations. Hypertension was present in $43.3 \%$ of our patients. This result is similar to that of Ridouane [9] who found out that $40.29 \%$ of his pa- 
tients were hypertensive. Obesity and diabetes favor hypertension in conformity with the literature.

Android obesity was present in all the men and $91 \%$ of women, with an average height of $109.18 \mathrm{~cm}$ among men and $115.45 \mathrm{~cm}$ among women. This result is closer to that of the study of Charfi [6] in which $99.9 \%$ had an android obesity with an average height of $113.77 \mathrm{~cm}$ among the men and $111.22 \mathrm{~cm}$ among the women.

Gynoid obesity was present in $9 \%$ of women. Contrary to the literature's data in which this type of obesity is frequent with the woman. This could be explained by the size of the sample.

More than half of the patients had a BMI comprises between 30 and 34.9 $\mathrm{kg} / \mathrm{m}^{2}$. This result is similar to that of Charfi [5] who found out an average body mass index of $35.5 \mathrm{~kg} / \mathrm{m}^{2}$.

Ten percent (10\%) of our patients had a morbid obesity. This result is dissimilar to that of the $16 \%$ found by Charfi [6]. This could be due to the size of the sample which is largely superior to ours.

In the study we found in conformity with the literature among our diabetic patients that $33 \%$ of them had a hypertriglyceridemia, $37 \%$ of them had a high LDL cholesterol and $40 \%$ of them had a HDL hypocholesterolemia .However, among our non-diabetic patients we found out respectively $10 \%, 30 \%, 20 \%$. This difference could be due to the fact the association of diabetes with obesity is the bench of metabolic complications. Charfi [6] found in his study a dyslipidemia in $60.1 \%$ of the cases (associating a hypertriglyceridemia with a high LDL cholesterol and a HDL hypocholesterolemia).

The difficulty for the medical care provision and the lack of auto-surveillance of glycaemia constitute an actual fact which contributes to a bad equilibrium of patients. The investigation has revealed that $87 \%$ of diabetic patients had a bad balancing of their diabetes based on glycated haemoglobin. This result is similar to that found by Bambatsi [10] 93.6\%.

Sixty eight point three percent $(68.3 \%)$ of our patients were indifferent to obesity.

That is explicated by the idea that weighing to control your weight is considered by several of our patients as the sign of social opulence and that does not necessitate an individualized medical care.

\section{Conclusions}

Obesity associated with diabetes is a supplementary factor of risk mainly for the android type of obesity which was predominant among the population of our study.

The dyslipidemia increases the cardiovascular risk threatening the vital prognosis of the patient. Our study has revealed that the frequency of the metabolic troubles was higher among the diabetic obese patients than among the non-diabetic obese patients mainly the hypertriglyceridemia. 


\section{References}

[1] Ciangura, C., Czernichow, S. and Oppert, J.-M. (2009) Obésité; Complications de l'obésité. Traité de Médecine Akos, 3-0790.

[2] Atlas du diabète de la FID. 8ème Édition. Consulté le 10/01/2018. http://www.diabetesatlas.org/

[3] Menta, I., Traore, D., Ba, H.O., Dougnon, O., et al. (2014) HTA chez le sujet jeune de 18 à 35 ans dans le Service de cardiologie Du CHUGabriel Toure. Research, 1, 1254.

[4] Traore, D., Drago, A.A., Nientao, I.A. and Sow, S.D. (2014) Risque podologique chez les patients diabétiques dans un centre de santé de reference de Bamako. Mali medical Tome XXIX N4: 1-6.

[5] Brahim, B.O., Dionadji, M., Mouanodji, M., Batakao, G. and Pathe, M.D. (2004) Profil lipidique de la population de N'DJAMENA. Black African Medicine, 51, 54.

[6] Charfi, N., Dammak, M., Mnif, M., Kaffel, N., et al. (2008) Profil Épidémiologique, Clinique, Métabolique et Nutritionnel de l'obésité dans la région de Sfax (Tunisie). Diabetes and Metabolism, 34, 95.

[7] Bâ, H.O., Traoré, A., Diarra, M.B., Maiga, A., et al. (2010) Facteurs de risque cardiovasculaire majeurs selon le sexe en milieu hospitalier. Mali Medical, XXV, 98.

[8] Assa, T. (2008) Etude sur le syndrome métabolique en médecine interne Thése, Med, Bamako, $\mathrm{N}^{\circ} 40$.

[9] Ridouane, S., Oulad Sayad, N. and Diouri, A. (2008) Prévalence du syndrome métabolique chez les patients obèses de l'hôpital de jour du service d'endocrinologie du CHU Med VI de Marrakech. Diabetes and Metabolism, 34, 82-83.

[10] Romarick, B. (2010) Contribution a l'étude de la dysfonction érectile chez le diabétique dans le $\mathrm{CHU}$ du point $\mathrm{G}$ et au centre national de lutte contre le diabète. Thèse, Med, Bamako, $\mathrm{N}^{\circ} 93$. 